\title{
Hemangioendotelioma mediastínico
}

\section{Sr. Director:}

El hallazgo casual de masas mediastínicas en el adulto conlleva a un diagnóstico diferencial amplio, donde las pruebas complementarias de imagen pueden ayudarnos a discernir entre patología maligna o benigna; sin embargo en ocasiones, podemos encontarnos con diagnósticos insospechados.

Se presenta el caso de una paciente mujer de 64 años de edad con antecedentes personales de tuberculosis pulmonar en la infancia, colicestectomizada y sin otros antecedentes médicos de interés, que en el contexto de un cuadro gripal se le solicita una radiografía de tórax, encontrándose como hallazgo incidental una masa mediastínica anterior. A la exploración física no se evidenció ningún hallazgo patológico y en los exámenes analíticos (hemograma y bioquímica general) practicadas solo se detectó unas cifras de colesterol y triglicéridos elevadas, siendo el resto de parámetros normal. La gasometría arterial basal demostró una PO2: $95 \mathrm{mmHg}$, una PCO2: 40 mmHg, un pH: 7,42, un HCO3: 24 y una saturación arterial de oxígeno del 98\%; se le llevó a cabo una tomografía axial computerizada (TAC) (Fig. 1) que objetivó la existencia de una masa de $4,5 \mathrm{~cm}$ de diámetro localizada en el espacio paratraqueal derecho con características tomodensitométricas sólidas y con imágenes cálcicas puntiformes centrales, siendo estos hallazgos compatibles con un timoma. Posteriormente es intervenida a través de esternotomía media, objetivándose una tumoración derecha que infiltra y engloba el confluente venoso yúgulo-subclavio derecho, realizándose exéresis de la tumoración en bloque con ligadura de venas sub-

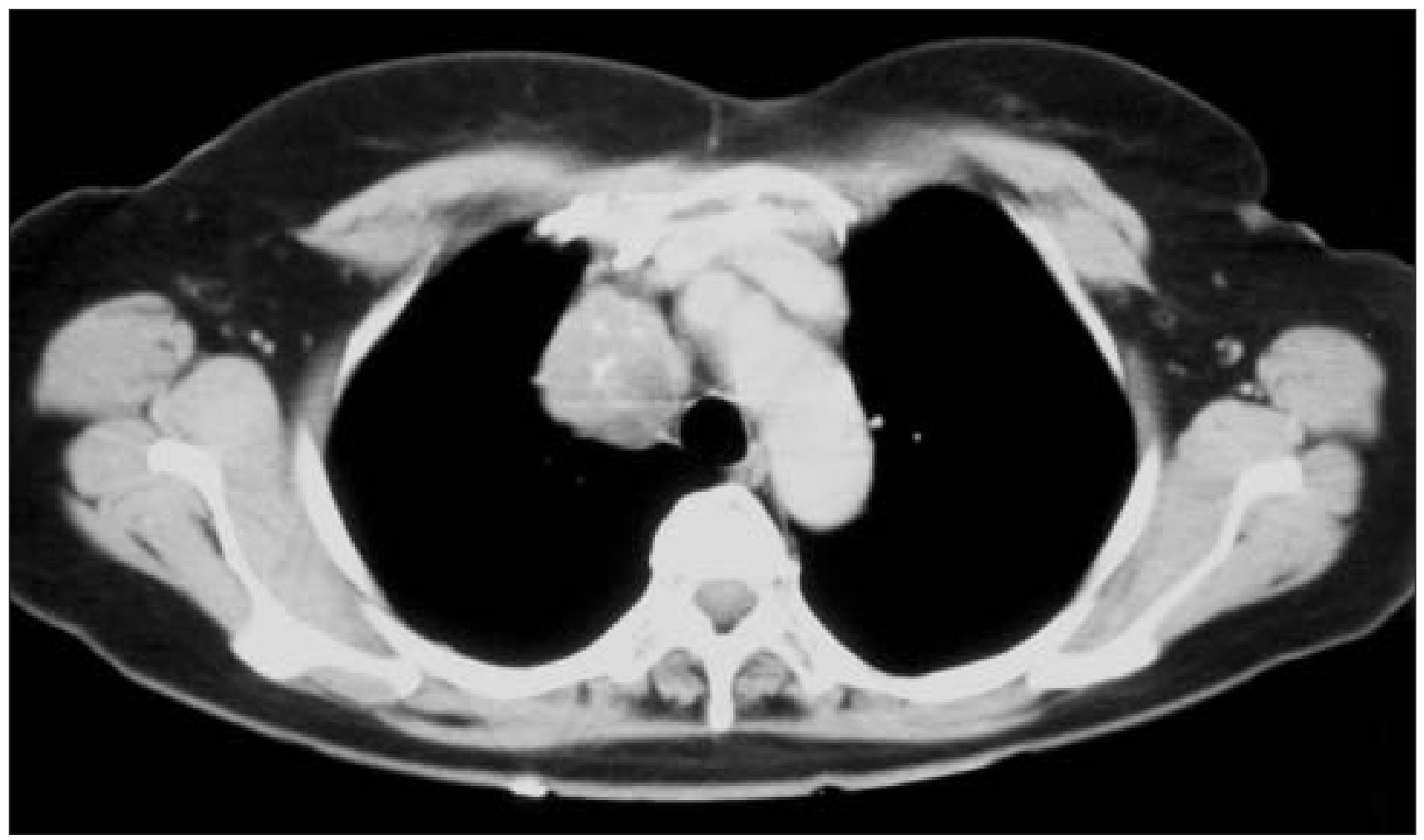

Figura 1. Masa mediastínica en el espacio paratraqueal derecho con imágenes cálcicas en su interior. 
clavia, yugular y reconstrucción de venas innominada y cava superior. El análisis de la pieza quirúrgica demostró que se trataba de una hemangioendotelioma epitelioide mediastínico.

El hemangioendotelioma epitelioide es un tumor de origen vascular muy poco frecuente, que en raras ocasiones puede manifestarse como una masa mediastínica ${ }^{1}$. En más de la mitad de los casos suele asentar en el tejido blando de las extremidades ${ }^{2}$, afectando a venas de mediano calibre como la femoral, iliaca o yugular, y cuando afecta al toráx, lo podemos encontrar como nódulos pulmonares, masas mediastínicas, masas pleurales o extrapleurales, como linfangitis carcinomatosa, o incluso como derrame pleural ${ }^{3}$. No posee predilección de edad ni sexo y no existen signos o síntomas que nos hagan sospechar de su presencia. Los métodos diagnósticos de elección son los de imagen, siendo la TAC de tórax y la resonancia magnética (RM) de elección, si bien cabe destacar, que lo son para el estadiaje, ya que muchas ocasiones suele ser un hallazgo casual en la radiografía de tórax ${ }^{4}$. Este tipo de neoplasias suelen poseer un comportamiento maligno de grado intermedio debido en su mayoría a un índice importante de recidivas locales y en ocasiones debido a la presencia de metástasis linfáticas y a órganos a distancia ${ }^{5}$. El tratamiento de elección es la cirugía, sin embargo debemos descartar la existencia de posibles metástasis previamente, ya que entonces debemos optar por tratamientos radioterápicos y quimioterápicos, aunque con peores resultados en la supervivencia ${ }^{4}$.

Los medios diagnósticos de imagen, en la actualidad, nos permiten en la mayoría de los casos, según los hallazgos encontrados, aventurar un origen, incluso la histología; sin embargo parece cierto en este caso, que las características de la lesión mediastínica nos han llevado a suponer un diagnóstico erróneo y por tanto a planificar una cirugía, de menor cabida a la que realmente luego tuvo que ser llevada. Este hecho nos lleva a pensar, que ante cualquier masa mediastínica, deberíamos realizar estudios más avanzados (RM o arteriografía) para delimitar y conocer en su caso la posible afectación o no de estructuras mediastínicas con vistas a planificar mejor la cirugía.

\author{
J. M. Hernández Pérez ${ }^{1}$, R. Gil Lorenzo², \\ A. Balan ${ }^{3}$, Freixinet Gilart $\mathbf{J}^{2}$ \\ ${ }^{1}$ Sección de Neumología \\ Hospital General de La Palma. Isla de La Palma. \\ ${ }^{2}$ Servicio de Cirugía Torácica \\ ${ }^{3}$ Servicio de Medicina Intensiva. \\ Hospital Dr. Negrín. \\ Las Palmas de Gran Canaria.
}

\section{Bibliografía}

1. Ortiz de Saracho y Bobo J, Zapatero Gaviria J, Fogue Calvo L, Pérez Rodríguez E, Zapatero Gaviria A. Hemangioendotelioma epitelioide mediastínico. An Med Intern (Madrid) 1994;11 (12):598-600.

2. Toursarkissian B, O'Connor W, Dillon M. Mediastinal Epitheloid Hemangioendothelioma. Ann Thorac Surg 1990;49: 680-685.

3. Belelaqua F, Valensi Q, Hulnick D. Epithelioid hemangioendothelioma. A rare tumor with variable prognosis presenting as a pleural effusion. Chest 1988;93:665-6.

4. Rubinowitz A, Moreira A, Naidich D. Mediastinal hemangioendothelioma: Radiologic-Pathologic correlation. J Comp Assist Tomogr 2000; 24 (5):721-723.

5. Weiss S, Enzinger F. Epithelioid hemangioendothelioma. A vascular tumor often mistaken for a carcinoma. Cancer 1982;50:970-981.
Correspondencia:

Dr. J. M. Hernández Pérez

Sección de Neumología

Hospital General de La Palma

C/ Buenavista de Arriba s/n

E-38710 Breña Alta. Isla de La Palma

jmherper@terra.es 